\title{
Regulation of Petunia Pollen Tube Growth by
}

\section{Phytohormones: Identification of Their Potential Targets}

\author{
Lidia Kovaleva ${ }^{1}$, Alexander Voronkov ${ }^{1}$, Ekaterina Zakharova ${ }^{2}$, Yuliya Minkina ${ }^{1}$, Galina Timofeeva ${ }^{1}$ and Igor \\ Andreev ${ }^{1}$ \\ 1. Timiryazev Institute of Plant Physiology, Russian Academy of Sciences (RAS), Botanicheskaya Street 35, Moscow 127276, Russia \\ 2. Department of Genetics, Biotechnology, Plant Breeding and Seed Science, Timiryazev Agricultural Academy, Moscow 127550 , \\ Russia
}

\begin{abstract}
It is known that cytoskeleton-dependent trafficking of cell wall and membrane components to apical plasma membrane (PM) coupled with ion transport across pollen PM is crucial for maintaining polar pollen tube growth. To elucidate whether plant hormones are involved in these processes, the effects of exogenous phytohormones, indole-3-acetic acid (IAA), abscisic acid (ABA), gibberellin $\mathrm{A}_{3}\left(\mathrm{GA}_{3}\right)$ and cytokinin (kinetin) on the growth, PM polarization, actin cytoskeleton (AC) organization and cytoplasmic $\mathrm{pH}\left(\mathrm{pH}_{\mathrm{c}}\right)$ of in vitro $4 \mathrm{~h}$-growing petunia pollen tubes were investigated. IAA, ABA and $\mathrm{GA}_{3}$ displayed the growth-stimulating effects and these were accompanied by orthovanadate-sensitive hyperpolarization of the PM. Fluorescent labeling the enzyme with $\mathrm{H}^{+}$-ATPase antibodies exhibited IAA- and ABA-induced lateral PM redistribution of it into the subapical zone of pollen tube PM. Pollen cultivation on the medium with latrunculin $\mathrm{B}$, the inhibitor of actin polymerization, resulted in inhibition of pollen tube growth and simultaneously in the drop of endogenous IAA content. The IAA-growth stimulating effect was correlated with increased content of actin filaments (AF) in both apical and subapical zones of tubes, while ABA and $\mathrm{GA}_{3}$ exerted the same effect but it was accompanied by redistributing F-actin only to apical zone. In contrast, kinetin decreased the total F-actin content and inhibited pollen tube growth. It has been shown that the $\mathrm{pH}_{\mathrm{c}}$ of growing pollen tubes is sensitive to the plant hormones. In the case of male gametophyte growing for 1, 2 and $4 \mathrm{~h}$, IAA induced alkalinization of the cytosol, while ABA and $\mathrm{GA}_{3}$ exerted qualitatively similar effect only after its growth for $1 \mathrm{~h}$ and $4 \mathrm{~h}$, respectively. Kinetin, in contrast, resulted in acidification of the cytosol. All these results, taken together, indicate, for the first time, potential targets of the phytohormone action in pollen tubes.
\end{abstract}

Key words: Actin cytoskeleton, petunia, plant hormones, $\mathrm{PM} \mathrm{H}^{+}$-ATPase, pollen tube.

\section{Introduction}

In plants, successful fertilization involves pollen tube growth through the pistil tissue towards the egg cells. A fine-tuned network of cellular processes is required to regulate the germination of pollen grains and the elongation of pollen tubes. These processes include a dynamic organization of the cytoskeleton, vesicle and protein trafficking, establishing intracellular tip-localized $\mathrm{Ca}^{2+}$ and $\mathrm{pH}$ gradients, an active metabolism and signal transduction pathways [1-8]. At present, understanding the operation of the highly coordinated regulatory pathways that control

Corresponding author: Lidia Kovaleva, professor, research field: pollination and fertilization in plants (hormonal signaling). the underlying processes remains to be most complex problem.

Earlier, significant differences in the hormonal status of the petunia pollen-pistil system after self-compatible and self-incompatible pollinations were revealed, which suggested a possible involvement of plant hormones in signal cascade of events in the course of the progamic phase of fertilization [9]. However, the mechanisms of hormone action and the possibility of hormones functioning as signal molecules in the pollen-pistil system remain so far to be unstudied. Recently, it has been shown that petunia pollen grain germination in vitro is accompanied by changes in the levels of plant hormones, such as ethylene, indole-3-acetic acid 
(IAA), abscisic acid (ABA), gibberellins and cytokinins, and is sensitive to the treatment by exogenous ones [10-12]. Most recent data [11, 13, 14] allowed us to put forward a hypothesis about hormonal signaling in polar growth of pollen tubes. Addressing this problem, the two important circumstances were taken into account. First, the plasma membrane (PM) $\mathrm{H}^{+}$-ATPase is known to energize the pollen PM for nutrient, ion and water uptake, and additionally its activity directly affects both the germination and growth of pollen tubes [7]. In addition, this enzyme may serve as a signaling target in osmosensing and osmoregulation of pollen tubes [15] and generally is capable of behaving as an essential node in their signaling network. Second, cytoskeleton-dependent trafficking of cell wall and membrane components is crucial for establishing and maintaining pollen tube growth [8].

In this connection, the purpose of the present work was to check a validity of the above hypothesis focusing on the interaction of plant hormones with the key players of polar pollen tube growth, namely the $\mathrm{H}^{+}$-ATPase in the PM and actin cytoskeleton (AC) of male gametophyte.

\section{Materials and Methods}

\subsection{Plants and Treatments}

Plants of petunia (Petunia hybrida L.) were collected from the nature and then propagated vegetatively in tubes on agar-solidified Murashige-Skoog (MS) medium in the climate-controlled chamber $\left(25^{\circ} \mathrm{C}, 16 \mathrm{~h}\right.$ photoperiod). The 45-day-old to 60-day-old plants were transferred into $5 \mathrm{~L}$ plastic vessels with soil and grown in the greenhouse under natural illumination. All experiments were done on freshly collected mature pollen.

$2 \mathrm{mg}$ of pollen was cultivated for $4 \mathrm{~h}$ in thermostat at $26^{\circ} \mathrm{C}$ on the medium containing $0.4 \mathrm{M}$ sucrose and $1.6 \mathrm{mM} \mathrm{H}_{3} \mathrm{BO}_{3}$. Plant hormones, IAA, ABA, $\mathrm{GA}_{3}$ and kinetin $(1 \mu \mathrm{M})$ were added to the medium simultaneously with pollen.
The pollen tubes were examined under the microscope Axio Imedger D1 equipped with Axio Cam MRm camera. The pollen tubes length was measured using AxioVision 4.8 software (Carl Zeiss, Germany). In each treatment, these measurements were made on 100 pollen tubes.

\subsection{Monitoring Hormone-Induced Changes in the Membrane Potential on the PM of Pollen Tubes}

As the activity of $\mathrm{PM} \mathrm{H}^{+}$-ATPase generates transmembrane proton gradient $\left(\Delta \mu \mathrm{H}^{+}\right)$, involving both $\Delta \mathrm{pH}$ and the membrane potential $(\Delta \psi)$, it was attempted to elucidate whether the $\Delta \psi$ is sensitive to exogenous plant hormones. For monitoring the membrane potential on the PM of growing pollen tubes, they were cultivated on the medium containing $0.4 \mathrm{M}$ sucrose and $1.6 \mathrm{mM} \mathrm{H}_{3} \mathrm{BO}_{3}$, thereafter they were transferred into the incubation buffer containing $0.3 \mathrm{M}$ sucrose and $25 \mathrm{mM}$ 2-( $N$-morpholino) ethanesulfonic acid-tris(hydroxymethyl) aminomethane (MES-Tris) (pH 6.9).

To this end, a possible sensitivity of $\Delta \psi$ on pollen tubes $\mathrm{PM}$ (negative inside) to plant hormones (IAA, $\mathrm{ABA}, \mathrm{GA}_{3}$ and kinetin) was tested with the use of cationic probe safranin $\mathrm{O}$, as described earlier by Voronkov et al. [13]. The hormones at concentration of $1 \mu \mathrm{M}$ were added to suspension of growing pollen tubes pre-equilibrated with the $\Delta \psi$-sensitive probe safranin $\mathrm{O}$ in $\mathrm{K}^{+}$-free assay medium. Hormone-induced changes in $\Delta \psi$ of pollen tubes were monitored by differential absorbance $\left(\mathrm{A}_{554}-\mathrm{A}_{524}\right)$ changes of the cationic probe. Spectrophotometric measurements were carried out with a double-wavelength spectrophotometer Hitachi-557 (Japan) at $25{ }^{\circ} \mathrm{C}$ in standard $1 \mathrm{~cm}$ cuvettes with continuously stirring their content with gentle air flow passing through pollen suspension in order to prevent its sedimentation in the course of experiments.

\subsection{Fluorescent Immunolabeling PM $H^{+}$-ATPase}

Pollen tubes were immediately fixed with $4 \%$ 
paraformaldehyde (PFA) in $10 \quad \mathrm{mM}$ phosphate-buffered saline (PBS: $2.68 \mathrm{mM} \mathrm{KCl}, 0.15$ $\mathrm{M} \mathrm{Na}_{2} \mathrm{HPO}_{4}$ and $0.086 \mathrm{M} \mathrm{KH}_{2} \mathrm{PO}_{4}$ ) overnight at $4{ }^{\circ} \mathrm{C}$. Samples were then washed in a regular salt rinse solution (RSRS: $10 \mathrm{mM}$ PBS, $0.15 \mathrm{M} \mathrm{NaCl}, 0.1 \%$ (vol/vol) Tween 20 and $0.8 \%$ bovine serum albumin (BSA)) and washed with $10 \mathrm{mM}$ PBS containing $0.8 \%$ BSA solution (PBS + BSA) to remove the Tween 20 [16]. After the application of rabbit anti- $\mathrm{H}^{+}-\mathrm{ATPase}$ antibodies (Agrisera, AS07 260; 1:300 dilutions in 10 mM PBS, 1\% BSA, pH 7.2), samples were incubated for $4 \mathrm{~h}$ at $37{ }^{\circ} \mathrm{C}$. After hybridization, samples were subjected to a series of vigorous washes, twice with a high-salt rinse solution (HSRS: $10 \mathrm{mM}$ PBS, $0.5 \mathrm{M}$ $\mathrm{NaCl}, 0.1 \%$ (vol/vol) Tween 20 and $0.1 \%$ BSA) for 10 min, once with RSRS for $10 \mathrm{~min}$, and washed with PBS + BSA. The chicken anti-rabbit $\lg \mathrm{G}(\mathrm{H}+\mathrm{L})$, DyLight 488 conjugated antibodies (Agrisera, AS10 831 ; $1: 500$ dilutions in $10 \mathrm{mM}$ PBS, $0.15 \mathrm{M} \mathrm{NaCl}, 1 \%$ BSA, pH 7.2) was incubated overnight at room temperature. After washing with RSRS twice for 5 min, specimens were mounted, covered with a coverslip and observed under fluorescent microscope (AxioImager $\mathrm{Z} 2$ with ApoTome, AxioCam MRm camera; filter set $65 \mathrm{HE}$ - excitation 475/30, emission 550/100; Carl Zeiss, Germany). Using AxioVision 4.8, the image of pollen tube was divided into eight equal $10-\mu \mathrm{m}$ parts starting from the tip, thereafter the profile reflecting distribution of fluorescence intensity on all pollen tube zones was constructed. At least 50 pollen tubes were monitoring in each of five replicates. The mean fluorescence intensity of DyLight 488 in each pollen tube zone was calculated using Microsoft Office Excel 2007 software.

\subsection{F-actin Visualization}

Plant hormones IAA, ABA, $\mathrm{GA}_{3}$ and kinetin (1 $\mu \mathrm{M})$, or inhibitor of actin polymerization, latrunculin $\mathrm{B}(0.2 \mathrm{nmol})$ were added to the medium after $2 \mathrm{~h}$ pollen germination, and subsequent cultivation was lasted for $2 \mathrm{~h}$.
Pollen tubes were fixed according to slightly modified method of Wang et al. [17] with 4\% PFA in the actin-stabilizating buffer containing $100 \mathrm{mM}$ Pipes, $1 \mathrm{mM} \mathrm{MgCl} 2,1 \mathrm{mM} \mathrm{CaCl} 2,75 \mathrm{mM} \mathrm{KCl}$ (pH 6.9) for $1 \mathrm{~h}$ (with vacuum infiltration for first $5 \mathrm{~min}$ ). Then, the samples were washed three times and permeated with the buffer containing $0.1 \%$ Triton X-100 and $1 \mathrm{mM}$ DTT for $1 \mathrm{~h}$. Pollen tube F-actin was stained with $0.66 \mu \mathrm{M}$ fluorescein isothiocyanate (FITC)-phalloidin in phosphate buffer, containing $0.15 \mathrm{M} \mathrm{NaCl}, 2.7 \mathrm{mM} \mathrm{KCl}, 1.2 \mathrm{mM} \mathrm{KH}_{2} \mathrm{PO}_{4}$ and 6.5 $\mathrm{mM} \mathrm{Na} \mathrm{HPO}_{4}$ for $20 \mathrm{~min}$. Thereafter, the samples were washed three times with phosphate buffer and examined under fluorescent microscope (AxioImager D1, AxioCam MRm camera; filter set 44-excitation 475/40, emission 530/50; Carl Zeiss, Germany). Equipment and software were from Carl Zeiss (Germany). Pollen tube image was divided into eight equal $10-\mu \mathrm{m}$ parts starting from the tip, and then the profile demonstrating the distribution of the fluorescence emission intensity in all pollen tube zones was constructed. The average values of fluorescence in each tube zone were evaluated using Microsoft office Excel 2003 software.

\subsection{Monitoring Hormone-Induced Changes in $\mathrm{pH}_{\mathrm{c}}$}

$\mathrm{pH}_{\mathrm{c}}$ of pollen tubes was evaluated after their preliminary loading with fluorescein diacetate (Serva, Germany) or 2',7'-bis-(2-carboxyethyl)-5(6') -carboxyfluorescein acetoxymethyl ester (BCECF-AM) (Sigma, United States) as described earlier by Andreev et al. [11]. Fluorescence at 530 $\mathrm{nm}$ excited at $440 \mathrm{~nm}\left(\mathrm{~F}_{440}\right)$ and $490\left(\mathrm{~F}_{490}\right) \mathrm{nm}$ was measured, and the ratio of $\mathrm{F}_{490} / \mathrm{F}_{440}$ as a measure of $\mathrm{pH}_{\mathrm{c}}$ [18] was calculated. Pollen tube growth was initiated at $26{ }^{\circ} \mathrm{C}$ in the medium containing $0.4 \mathrm{M}$ sucrose and $1.6 \mathrm{mM} \mathrm{H}_{3} \mathrm{BO}_{3}$. Before measurements, the freshly collected pollen grains were incubated at $26^{\circ} \mathrm{C}$ for $1 \mathrm{~h}$ in the buffer containing $0.3 \mathrm{M}$ sucrose and $25 \mathrm{mM}$ Mes-Tris, $\mathrm{pH}$ 6.9. Then pollen tubes were placed for $15 \mathrm{~min}$ into the loading medium 
containing $5 \mathrm{mM}$ pH-indicator, thereafter hormones (IAA, $\mathrm{ABA}, \mathrm{GA}_{3}$, kinetin) at concentration of $5 \mu \mathrm{M}$ were added. $\mathrm{pH}_{\mathrm{c}}$ was measured in each $5 \mathrm{~min}$ for 20 min. Fluorescent measurements were performed on a Hitachi 850 fluorescence spectrophotometer (Hitachi, Japan) in standard $1 \mathrm{~cm}$ cuvettes without continuous stirring the samples in the course of the experiment.

\subsection{Determination of Endogenous Plant Hormone Contents}

The contents of free forms of IAA, ABA, $\mathrm{GA}_{3}$ and cytokinins (the sum of zeatin, zeatin riboside and dihydrozeatin) were determined in pollen/pollen tubes after 0,1 and $4 \mathrm{~h}$ of their cultivation. Pollen/pollen tubes were separated from medium on the paper filter. The material was fixed as described by Skorobogatova et al. [19]. Samples were analyzed by high performance liquid chromatography (HPLC).

\subsection{Statistical Analysis}

Experiments were performed in three to five replicates with three recording in each of them. The significance of differences was estimated with the
Student's $t$ criterion at $P \leq 0.05$. The data are expressed as the mean values and standard errors.

\section{Results}

\subsection{Effects of Plant Hormones on Pollen Tube Growth}

Earlier, the impact of plant hormones of IAA, ABA, $\mathrm{GA}_{3}$ and cytokinin, at concentrations from $10^{-12} \mathrm{M}$ to $10^{-3} \mathrm{M}$ on petunia pollen tube growth was studied (Tables 1 and 2) [10, 12], and these effects are dose-dependent. In the present work, in order to compare effects of all the exogenous hormones, they were used at concentration of $1 \mu \mathrm{M}$. As shown in Fig. 1, IAA, ABA and $\mathrm{GA}_{3}$ at this concentration stimulated the process in question, while cytokinin, in contrast, inhibited pollen tube growth.

\subsection{Effects of Plant Hormones on Pollen PM $H^{+}$-ATPase}

3.2.1 Effects of Hormones on the Membrane Potential on Pollen Tube PM

The effect of hormones on the membrane potential on pollen tube PM was shown in Fig. 2. An addition of IAA to pollen tube suspension immediately initiated

Table 1 Effects of exogenous plant hormones on in vitro germination of petunia pollen grains after $0.5 \mathrm{~h}$ of cultivation on the medium containing $0.4 \mathrm{M}$ sucrose and $1.6 \mathrm{mM} \mathrm{H}_{3} \mathrm{BO}_{3}$.

\begin{tabular}{lllllll}
\hline \multirow{2}{*}{ Plant hormone } & \multicolumn{5}{c}{ In vitro germination of petunia pollen grains at different concentration } \\
\cline { 2 - 7 } & $\times 10^{-12} \mathrm{M}$ & $\times 10^{-10} \mathrm{M}$ & $\times 10^{-8} \mathrm{M}$ & $\times 10^{-6} \mathrm{M}$ & $\times 10^{-4} \mathrm{M}$ & $\times 10^{-3} \mathrm{M}$ \\
\hline $\mathrm{GA}_{3}$ & 278 & 235 & 227 & 219 & 200 & 163 \\
$\mathrm{ABA}$ & 327 & 291 & 198 & 168 & 151 & 112 \\
$\mathrm{IAA}$ & 151 & 136 & 127 & 121 & 101 & 0 \\
6-BAP & 100 & 83 & 75 & 70 & 65 & 0 \\
\hline An & & &
\end{tabular}

An intensity of this process in control $=100 \%$. The data are the means obtained from three independent experiments carried out in two replicates $(n=6)$ [12].

Table 2 Effects of exogenous plant hormones on in vitro growth of petunia pollen tube after $0.5 \mathrm{~h}$ of pollen cultivation on the medium containing $0.4 \mathrm{M}$ sucrose and $1.6 \mathrm{mM} \mathrm{H}_{3} \mathrm{BO}_{3}$.

\begin{tabular}{lllllll}
\hline \multirow{2}{*}{ Plant hormone } & \multicolumn{5}{c}{ In vitro growth of petunia pollen tube at different concentration } \\
\cline { 2 - 7 } & $\times 10^{-12} \mathrm{M}$ & $\times 10^{-10} \mathrm{M}$ & $\times 10^{-8} \mathrm{M}$ & $\times 10^{-6} \mathrm{M}$ & $\times 10^{-4} \mathrm{M}$ & $\times 10^{-3} \mathrm{M}$ \\
\hline $\mathrm{GA}_{3}$ & 299 & 228 & 228 & 197 & 157 & 118 \\
$\mathrm{ABA}$ & 259 & 165 & 157 & 118 & 118 & 94 \\
$\mathrm{IAA}$ & 252 & 252 & 238 & 239 & 220 & 0 \\
6-BAP & 100 & 100 & 100 & 100 & 100 & 0 \\
\hline An & & &
\end{tabular}

An intensity of this process in control $=100 \%$. The data are the means obtained from three independent experiments carried out in two replicates $(n=6)[12]$. 


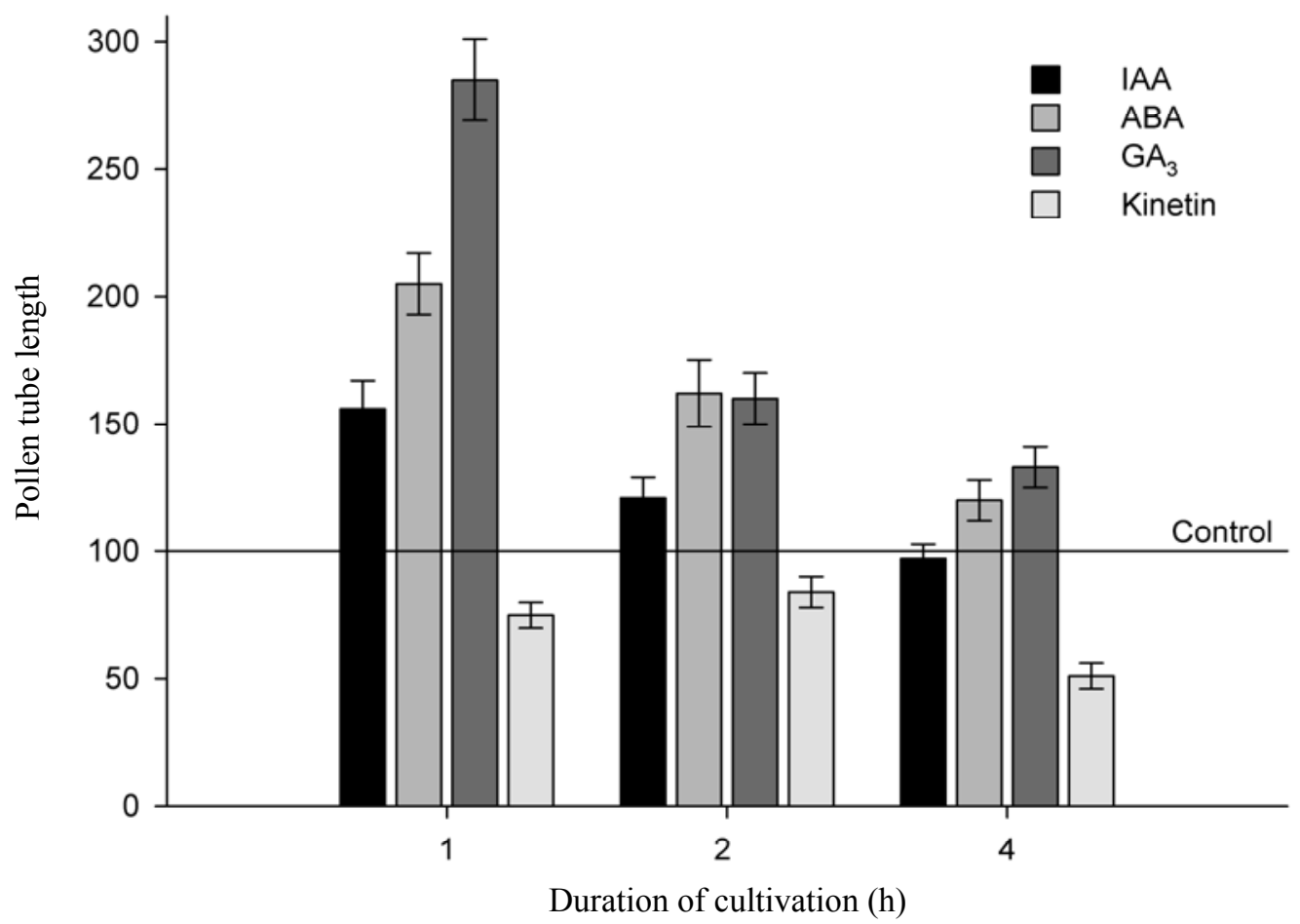

Fig. 1 Effects of plant hormones on petunia pollen tube growth on medium containing $0.4 \mathrm{M}$ sucrose $+1.6 \mathbf{m M ~ H}_{3} \mathrm{BO}_{3}$. Pollen tube length in control group is $100 \%$. Data represent the mean from independent experiments $(n=6-10)$. Result significance was assessed with the Student's $t$-test at $P \leq 0.05$.

their membrane hyperpolarization, as judged by fluorescence quenching of safranin $\mathrm{O}$ (Fig. 2a). In fact, a similar effect took place also in the presence of ABA and $\mathrm{GA}_{3}$ (Figs. 2c and 2e). Reversal of the hormone-induced fluorescence quenching due to leakage of the dye was observed after addition of 60 $\mathrm{mM} \mathrm{KCl}$ to pollen tubes suspension as a result of the depolarization of the pollen membrane (Figs. 2a, 2c and 2e).

To highlight the contribution of $\mathrm{H}^{+}$-ATPase pumps to the PM hyperpolarization due to plant hormones, orthovanadate, a well known specific inhibitor of plant PM $\mathrm{H}^{+}$-ATPase, was used. Application of $200 \mu \mathrm{M}$ orthovanadate completely abolished the effect caused by IAA or ABA or $\mathrm{GA}_{3}$ (Figs. 2b, 2d and 2f). These findings indicate that the proton pump was active and had an electrogenic component; it is most likely involved in the hormone-induced hyperpolarization of the PM. Kinetin has no effect on the membrane potential of pollen tubes (Fig. 2g).
3.2.2 Sensitivity of the Hormone-Induced PM Hyperpolarization in Pollen Tubes to External $\mathrm{Ca}^{2+}$

The sensitivity of hormone-induced PM hyperpolarization in pollen tubes to external $\mathrm{Ca}^{2+}$ was shown in Fig. 3. It is known that an action of plant hormones, such as IAA and $\mathrm{ABA}$ or $\mathrm{GA}_{3}$, in plant cells may be mediated by transient increase in cytosolic free $\mathrm{Ca}^{2+}$ level [20]. Therefore, in the last series of experiments, it was checked whether the hormone-induced membrane hyperpolarization depends on external $\mathrm{Ca}^{2+}$ entry into the growing pollen tubes. For this purpose, an effect of $\mathrm{Ca}^{2+}$ depletion of the assay medium with the $\mathrm{Ca}^{2+}$ chelator ethylene glycol-bis( $\beta$-aminoethylether)-N,N,N',N'tetraacetic acid (EGTA) (Figs. 3c, 3f and 3i), and also the application of verapamil, the known blocker of $\mathrm{Ca}^{2+}$ channels in cell membranes were studied (Figs. $3 b, 3 e$ and $3 h)$.

Fig. 3c shows that the absorbance change of safranin $\mathrm{O}$ only slightly increased in response to IAA 

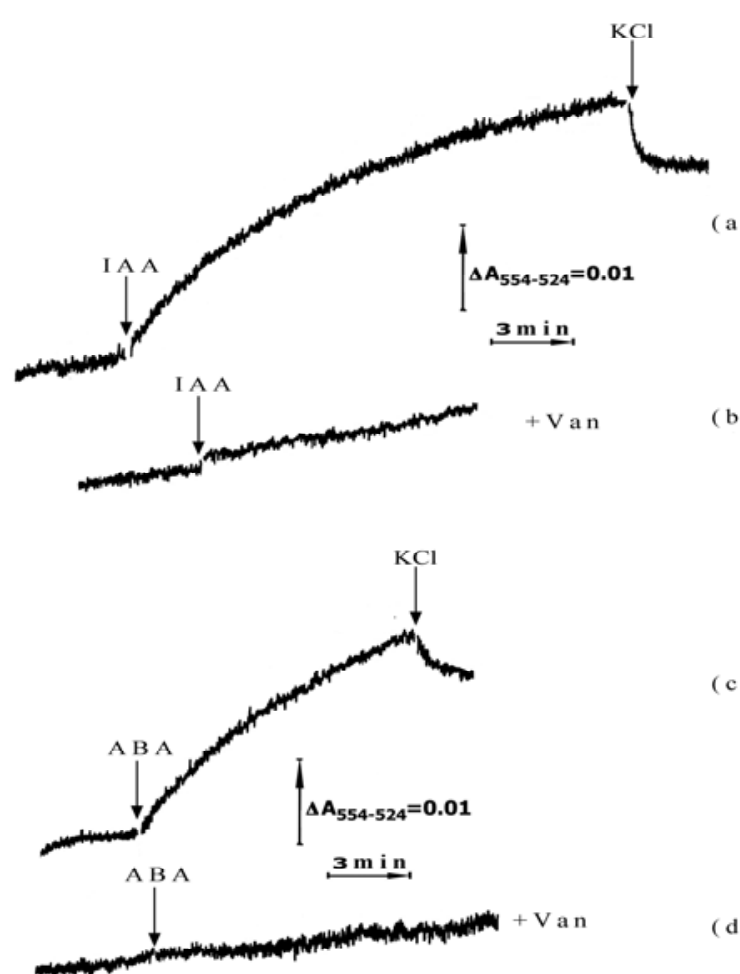

(a)

(b)

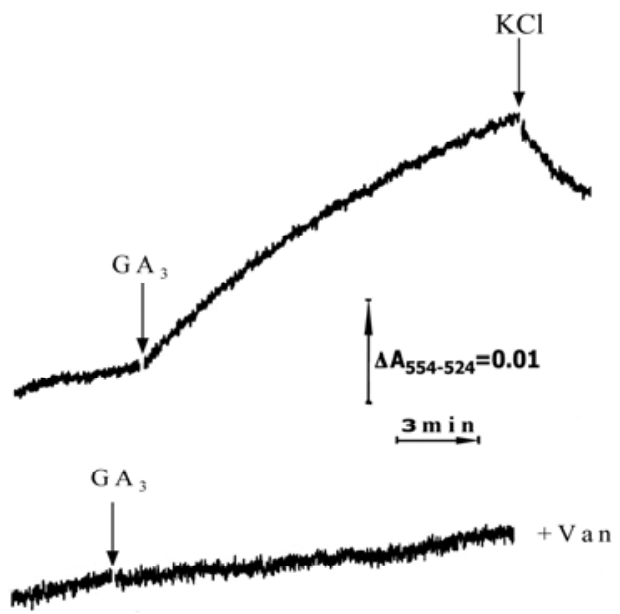

(c)

(d)
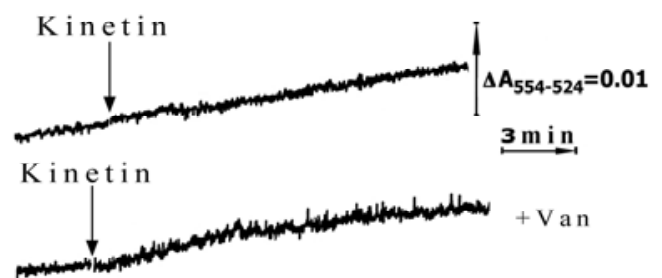

e)

Fig. 2 Hyperpolarization of the PM of petunia pollen tubes triggered by plant hormones and assayed by the potential-sensitive dye safranin $O$.

$1 \mu \mathrm{M}$ IAA (a), $1 \mu \mathrm{M}$ ABA (c), $1 \mu \mathrm{M} \mathrm{GA}_{3}$ (e) and $1 \mu \mathrm{M}$ kinetin (g) with $60 \mathrm{mM} \mathrm{KCl}$ and $200 \mu \mathrm{M}$ orthovanadate (+Van) (b, d, f, h) were added to pollen tube suspension in the $\mathrm{K}^{+}$-free assay medium containing $10 \mu \mathrm{M}$ safranin $\mathrm{O}$. Representative kinetic curves were from three independent experiments.
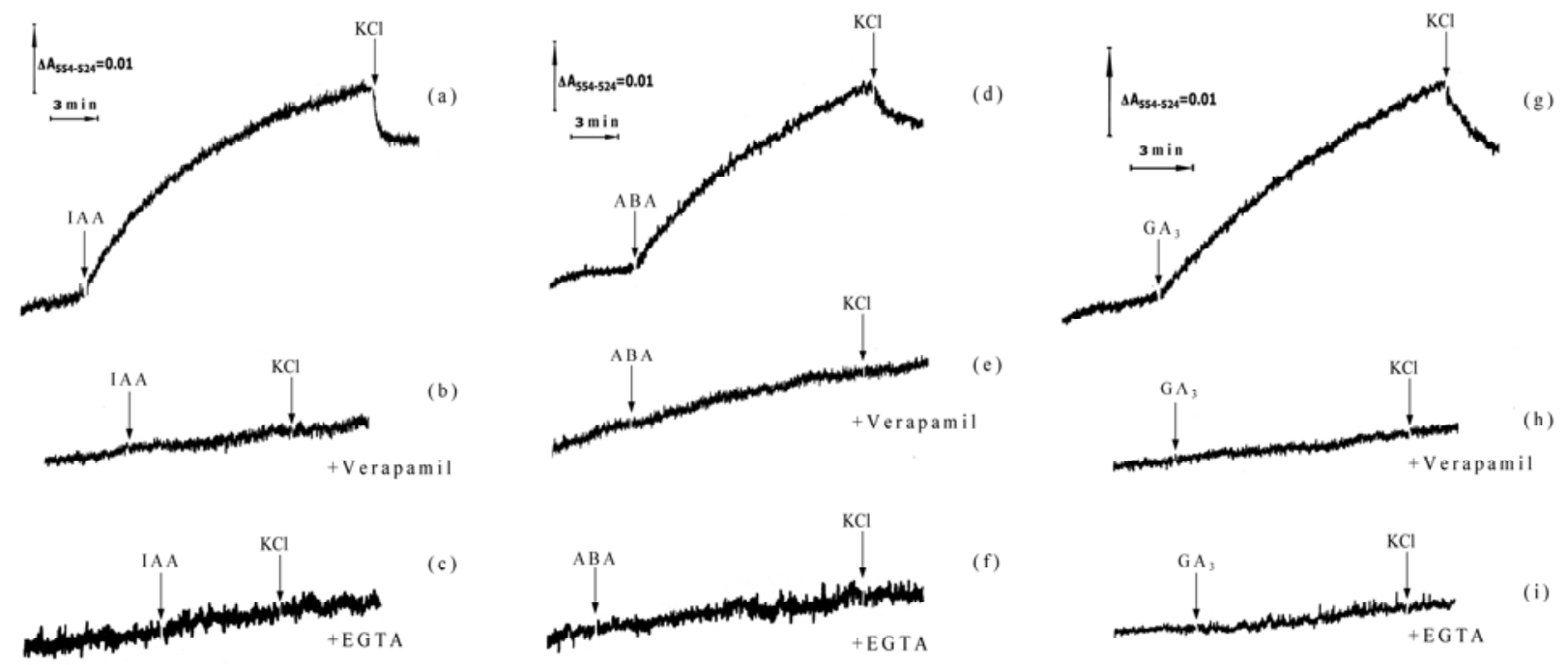

(f)

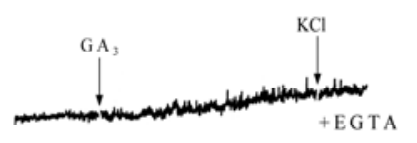

(i)

Fig. 3 Sensitivity of the hormone-induced PM hyperpolarization of petunia pollen tubes to verapamil and removing of $\mathrm{Ca}^{2+}$ from the external medium with EGTA.

$1 \mu \mathrm{M}$ IAA (a), $1 \mu \mathrm{M}$ ABA (d) and $1 \mu \mathrm{M} \mathrm{GA}_{3}$ (g) with $60 \mathrm{mM} \mathrm{KCl}, 100 \mu \mathrm{M}$ verapamil (b, e, h) and $1 \mathrm{mM}$ EGTA (c, f, i) were added to pollen tube suspension in the $\mathrm{K}^{+}$-free assay medium containing $10 \mu \mathrm{M}$ safranin $\mathrm{O}$. Representative kinetic curves were from three independent experiments. 
addition to pollen tube suspension, when the assay medium was supplied with $0.5 \mathrm{mM}$ EGTA. It is worth noting that, although the assay medium did not contain $\mathrm{Ca}^{2+}$, this cation might indeed present as impurities in both pollen tube preparations and chemicals. In fact, a similar inhibiting effect of the EGTA-induced $\mathrm{Ca}^{2+}$ depletion of the assay medium was observed also in the case of the ABA- or $\mathrm{GA}_{3}$-induced hyperpolarization of the pollen tubes (Figs. 3f and 3i). The observed inhibitory action of EGTA related to dramatic decline of $\mathrm{Ca}^{2+}$ level in the external medium may be attributed to prevention of external $\mathrm{Ca}^{2+}$ entry into the pollen tubes through the PM. This interpretation is supported, as revealed here, by a qualitatively similar inhibiting effect also induced by verapamil. As shown in Figs. 3b, 3e and 3h, this $\mathrm{Ca}^{2+}$ channel blocker abolished completely both the IAA-, ABA- and $\mathrm{GA}_{3}$-induced hyperpolarization of the PM of growing pollen tubes, thereby resembling the effect caused by EGTA.

3.2.3 Effects of Plant Hormones on Lateral PM Allocation of Pollen Tube PM H${ }^{+}$-ATPase

The effects of plant hormones on lateral PM

allocation of pollen tube PM H $\mathrm{H}^{+}$-ATPase were shown in Fig. 4. In the control test, pollen tubes were cultivated for $4 \mathrm{~h}$ in the standard medium, and thereafter they were treated with anti- $\mathrm{H}^{+}$-ATPase antibodies. The pollen tube $\mathrm{PM} \mathrm{H}^{+}$-ATPase is mainly localized in the zone $10-20 \mu \mathrm{m}$ from the tip of the tube, as follows from the pattern of lateral fluorescent label distribution in the tube PM (Fig. 4a). As shown in Figs. $4 \mathrm{~b}$ and $4 \mathrm{c}$, pollen tubes cultivated in the same medium in the presence of $1 \mu \mathrm{M}$ IAA or ABA displayed a different fluorescent label distribution in pollen tube PM, indicating preferred localization of PM $\mathrm{H}^{+}$-ATPase in zone $20-40 \mu \mathrm{m}$ from the tip of tubes. The effect of ABA appeared to be most evident (Figs. $4 \mathrm{c}$ and 4f). Pollen tubes treated with $1 \mu \mathrm{M} \mathrm{GA}_{3}$ and kinetin, unlike those treated with IAA or ABA, did not display clear response of the fluorescent label distribution in the pollen tube PM, and only slight enough fluorescence was observed along the entire length of pollen tube (Figs. $4 \mathrm{~d}$ and $4 \mathrm{e}$ ). Pollen tubes treated with $1 \mu \mathrm{M}$ kinetin displayed extremely slight fluorescence intensity in throughout all their length at a distance of 10-70 $\mu \mathrm{m}$ from the tip (Fig. 4e).
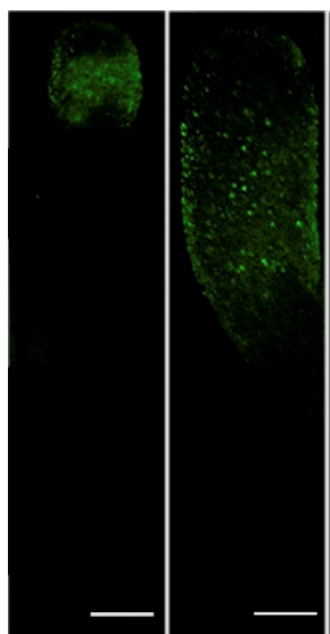

(b)

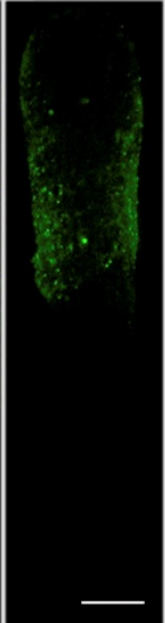

(c)

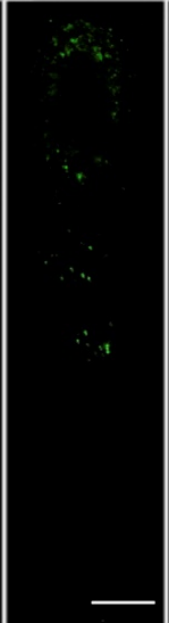

(d)

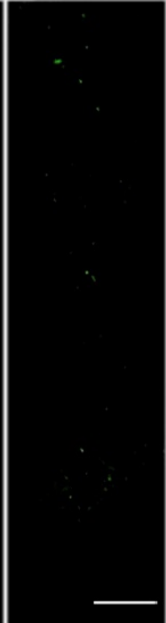

(e)

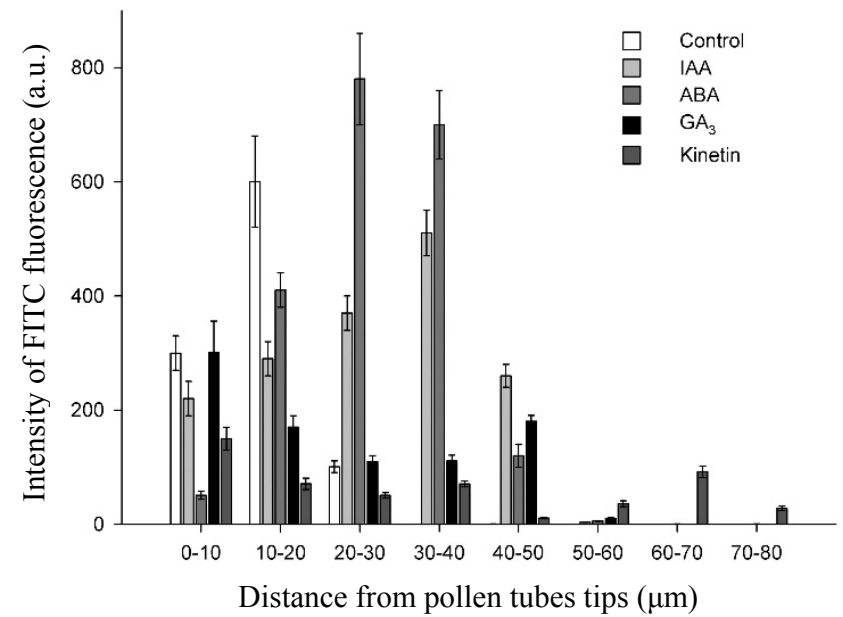

(f)

Fig. 4 Effects of IAA, ABA, GA ${ }_{3}$ and kinetin on the membrane allocation of the $\mathrm{PM}^{+}$-ATPase in petunia pollen tubes labeled with DyLight 488 and examined under AxioImager $Z 2$ with ApoTome. Scale bar $=10 \mu \mathrm{m}$.

(a) Control (pollen tubes cultivated for $4 \mathrm{~h}$ ); (b) after treatment of pollen tubes with $1 \mu \mathrm{M} \mathrm{IAA}$; (c) after treatment of pollen tubes with $1 \mu \mathrm{M} \mathrm{ABA}$; (d) Pollen tubes treated with $1 \mu \mathrm{M} \mathrm{GA}_{3}$; (e) pollen tubes treated with $1 \mu \mathrm{M}$ kinetin; (f) the relative fluorescence intensities measured using AxioVision 4.8 software. 


\subsection{Effects of Plant Hormones on AC}

Dynamics of individual hormone content in pollen tubes germinating on the medium containing $0.2 \mathrm{nmol}$ latrunculin B (inhibitor of actin polymerization) resulted in the inhibition of male gametophyte growth, due to the disturbance of AC organization. This effect was accompanied by a sharp decrease (practically to zero) in IAA content, while pollen tube growth on the medium without latrunculin B was accompanied by a gradual rise of this hormone (Fig. 5). Dynamics of $\mathrm{GA}_{3}$ content in growing pollen tubes did not undergo any sharp changes on both media, namely it increased (to $1,000 \mathrm{ng} / \mathrm{g}$ ) after $4 \mathrm{~h}$ cultivation on the medium without inhibitor, and on the contrary, it decreased to $500 \mathrm{ng} / \mathrm{g}$ in pollen tubes cultivating on the medium with latrunculin B (Fig. 5). The dynamics of cytokinin and $\mathrm{ABA}$ content was different (Fig. 5). For ABA in pollen tubes growing on both the media, it decreased to $0 \mathrm{ng} / \mathrm{g}$ throughout $1 \mathrm{~h}$ cultivation. In the case of cytokinin, its content increased during the first hour of cultivation, in both control and latrunculin B-treated pollen tubes, but this increase was less pronounced in the medium with latrunculin $\mathrm{B}$ as compared to the control. By $4 \mathrm{~h}$ of the cultivation, the contents of $\mathrm{ABA}$ and cytokinin in both the control and experimental pollen tubes appeared to be similar.

Furthermore, this possibility was investigated by following the putative hormone-induced changes in the extent of $\mathrm{AC}$ after preliminary labeling $\mathrm{F}$-actin with FITC-phalloidin. In these experiments, a fluorescence

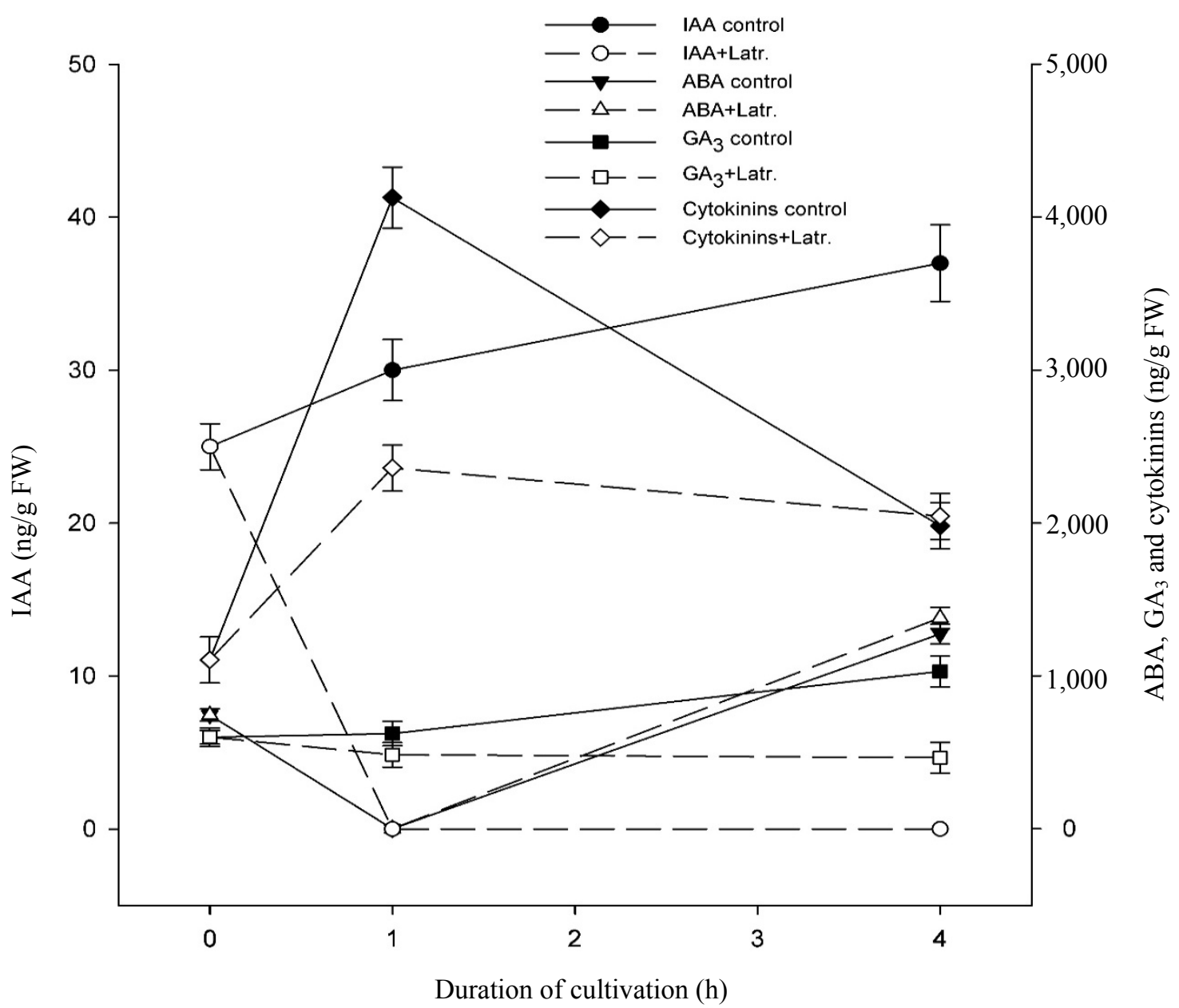

Fig. 5 Dynamics of plant hormone contents in 4-h-grown petunia male gametophyte under cultivation in two mediums: 0.3 M sucrose + $1.6 \mathrm{mM} \mathrm{H}_{3} \mathrm{BO}_{3}$ (-Latr) and $0.3 \mathrm{M}$ sucrose + $1.6 \mathrm{mM} \mathrm{H}_{3} \mathrm{BO}_{3}+0.2 \mathrm{nmol}$ latrunculin $\mathrm{B}$ (+Latr).

Data present the mean of three independent experiments. 
intensity measured in basal, subapical and apical zones of growing pollen tubes was considered as a value reflecting actin filaments (AF) density.

As shown in Figs. $6 \mathrm{a}$ and $6 \mathrm{~b}$, an addition of $1 \mu \mathrm{M}$ IAA to the cultivation medium led to the increase in the total amount of AF by $37 \%$ of their total pool in the pollen tube, being the greatest in both subapical and apical pollen tube zones known to be most important for polar tube growth [14]. In the case of ABA at the same concentrations, somewhat different results were obtained, and this was reflected in slight increase in total content of AF (up to 10\%) and $15 \%$-redistribution of AF to the apical zone of the tubes (Figs. 6a and 6b). Stimulating effect of $\mathrm{GA}_{3}$ on the pollen tube growth was accompanied by the increase in the total content of AF by $20 \%$ in apical and subapical zones and its drop in basal zone of growing pollen tubes, whereas total amount of AF in the latter remained unchanged (Figs. 6a and 6b).

Effect of kinetin, unlike that of IAA, was expressed in the decrease in AF amount by $40 \%$ as compared to the control (Fig. 6a) [14]. Pollen cultivation on the medium with the hormone resulted in the decrease in AF density along the length of the pollen tubes (Fig. 6b). All these effects of kinetin are apparently in accordance with its inhibiting effect on pollen tube growth.

Thus, the data presented here indicate that the AC organization in growing petunia pollen tubes is sensitive to exogenous hormones. It should be noted that among all hormones, IAA exerted the strongest effect on F-actin, implying that this hormone is one of the most important factors determining polar pollen tube growth.

\subsection{Effects of Plant Hormones on $\mathrm{pH}_{c}$}

Feijo et al. [2] provided evidence that the growing pollen tubes possess a $\mathrm{pH}$ gradient. The cytoplasmic $\mathrm{pH}\left(\mathrm{pH}_{\mathrm{c}}\right)$ of non-germinated and germinating petunia pollen grains markedly changed in response to the addition of IAA, ABA or $\mathrm{GA}_{3}$ [11].

As shown in Fig. 7, the effects of hormones on $\mathrm{pH}_{\mathrm{c}}$ of germinating pollen grains and growing pollen tubes appeared to be different as well.

In $1 \mathrm{~h}$-grown pollen tubes, IAA and ABA induced a relatively rapid cytosol alkalization, which was not reversed during experiment (Fig. 7a). Kinetin, in contrast, acidified the cytosol.

In 2 h-grown pollen tubes, only the above effect of IAA expressed in cytosol alkalinization was kept,

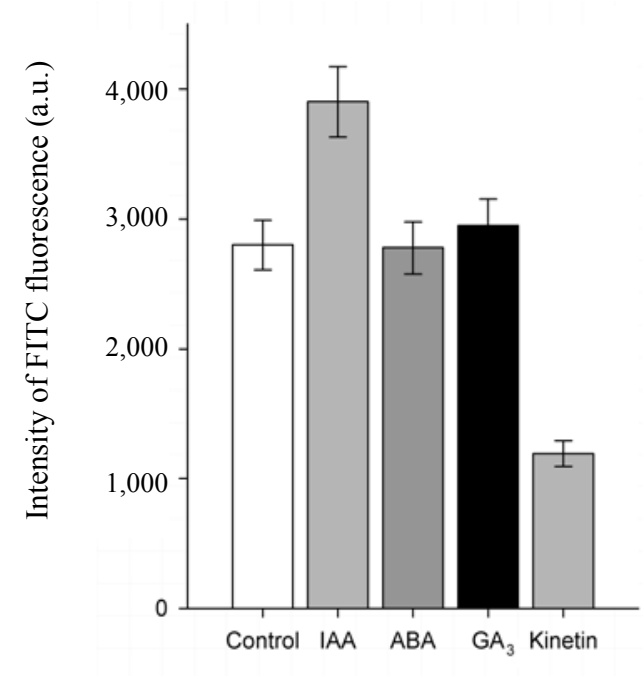

(a)

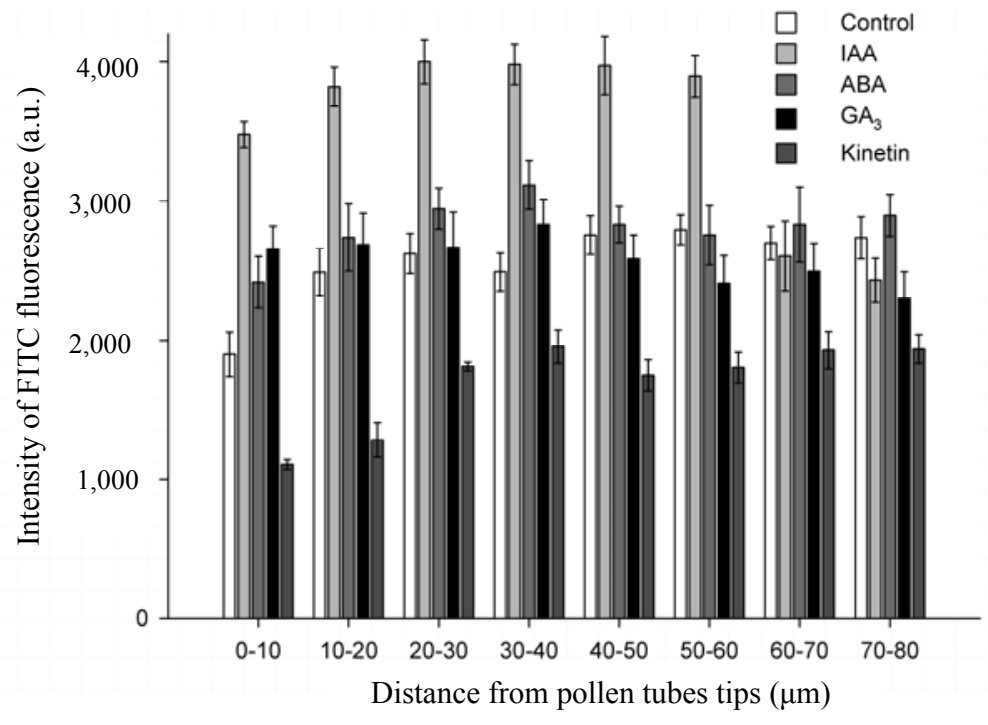

(b)

Fig. 6 IAA, ABA, GA 3 and kinetin effects on organization of petunia pollen tube F-actin stained with FITC-phalloidin. Difference significance was assessed with the Student's $t$-criterion at $P \leq 0.05$. 

Identification of Their Potential Targets

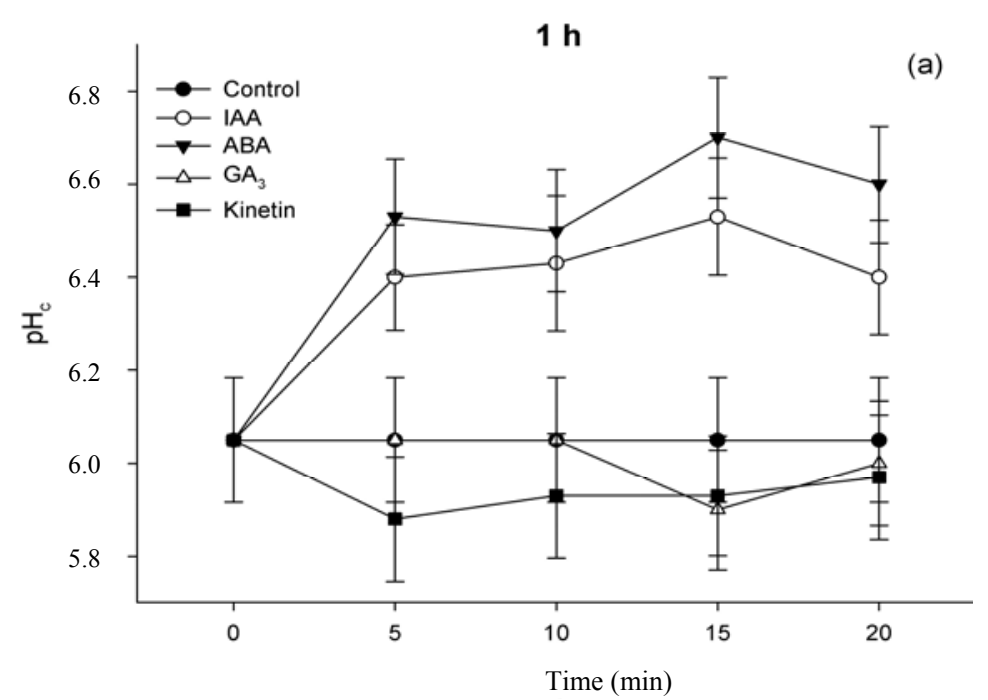

(b)
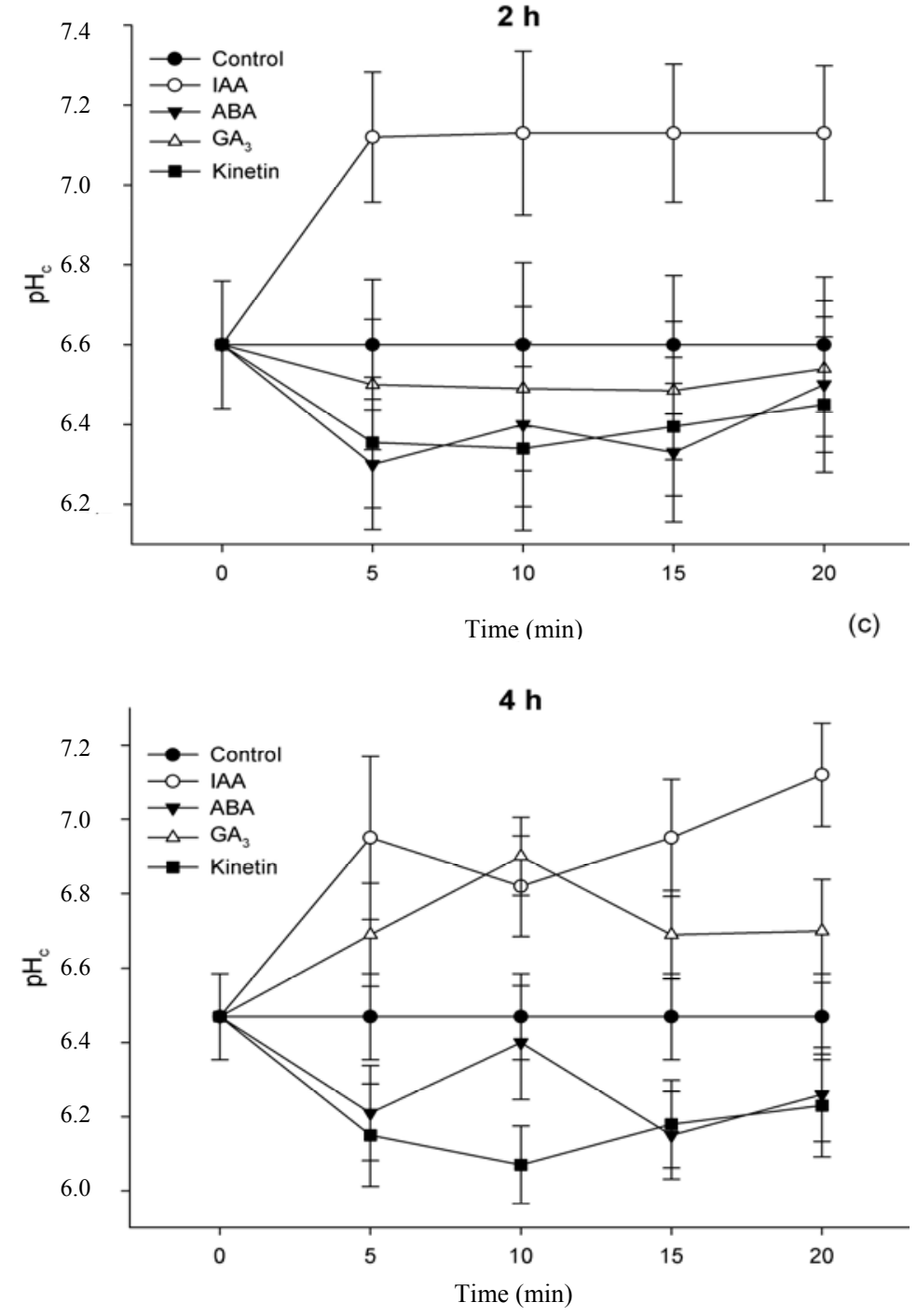

Fig. 7 Effects of plant hormones on $\mathrm{pH}_{\mathrm{c}}$ of petunia pollen tubes grown for $1 \mathrm{~h} \mathrm{(a),} 2 \mathrm{~h} \mathrm{(b)}$ and $4 \mathrm{~h}$ (c).

$\mathrm{IAA}, \mathrm{ABA}, \mathrm{GA}_{3}$ and kinetin at concentration of $5 \mu \mathrm{M}$ were added to the suspension of pollen tubes 10 min before fluorescence measurements. Data represent the mean values from 4-5 independent experiments. 
while $\mathrm{ABA}, \mathrm{GA}_{3}$ and kinetin had practically no such an effect and, in contrast, exerted only slight enough acidification of the cytosol (Fig. 7b).

In the case of 4 h-grown pollen tubes, the same hormones at concentration of $5 \mu \mathrm{M}$ induced relatively fast and significant changes in $\mathrm{pH}_{\mathrm{c}}$ (Fig. 7c). This value increased in the presence of both IAA and $\mathrm{GA}_{3}$, with in the presence of IAA only its gradual elevation took place. $\mathrm{GA}_{3}$ induced similar effect only for the first $10 \mathrm{~min}$. Although a gradual change in $\mathrm{pH}_{\mathrm{c}}$ was induced by kinetin as well, this effect was qualitatively different and expressed in cytoplasm acidification. ABA, like kinetin, induced also a relatively fast and substantial decrease in $\mathrm{pH}_{\mathrm{c}}$.

It needs to note that the modulation of $\mathrm{pH}_{\mathrm{c}}$ by the hormones as observed here in $4 \mathrm{~h}$-grown pollen tubes differs by its character from that caused by the same hormones for $1 \mathrm{~h}$ - and $2 \mathrm{~h}$-germined pollen grains. This argues likely in favor of that hormones can function at different stages of total signaling network regulating very complex process of pollen grain germination and pollen tube growth.

It is quite possible that the effects observed here reflect the regulation of $\mathrm{pH}_{\mathrm{c}}$ by hormones, and the hormone-induced alkaline $\mathrm{pH}_{\mathrm{c}}$ shift is likely mediated by the activity of $\mathrm{PM} \mathrm{H}^{+}$-ATPase of growing pollen tubes putatively involved in cytosolic $\mathrm{pH}$ homeostasis.

\section{Discussion}

The results presented clearly show that the

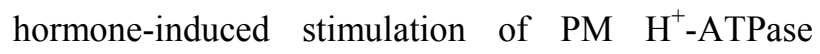
activity might be involved in promoting pollen tube polar growth by applied plant hormones. This conclusion is supported by the orthovanadate-sensitive hyperpolarization of pollen $\mathrm{PM}$ observed in the presence of IAA, ABA and $\mathrm{GA}_{3}$. In accordance with recent data on important role of this enzyme in pollen tube polar growth [7], it is not surprising that the growth-stimulating action of the hormones most likely involves their impact on the proton pump. One more hormonal effect related to their action on pollen PM
$\mathrm{H}^{+}$-ATPase is expressed in the change of its lateral membrane allocation in pollen tube PM. As noted above, polar localization of $\mathrm{H}^{+}$-ATPase in pollen PM and its absence from apical region appear to be the feature inherent in growing pollen tubes [21]. Therefore, the revealed hormonal effect contributes to the polarization of pollen tubes as a condition required for growth process.

An important question arose whether the observed

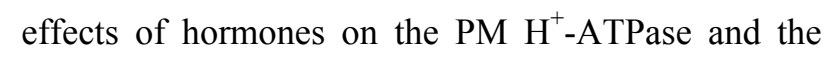
organization of $\mathrm{AC}$ are closely related. Although at present it is difficult to answer this question, a central modulator or player here may be $\mathrm{Ca}^{2+}$ as well-known second messenger capable of involving in several hormone signaling pathways. Indeed, $\mathrm{Ca}^{2+}$ is capable to be an organizer of cell polarity in plants [22]. In growing pollen tubes, this cation can mediate the effects of hormones related to both increased activity of $\mathrm{PM} \mathrm{H}^{+}$-ATPase, its polar localization in pollen tube $\mathrm{PM}$ and also the organization of the AC. This possibility is supported by the involvement of $\mathrm{Ca}^{2+}$ ions as a second messenger in various hormone-dependent processes including the activation of PM $\mathrm{H}^{+}$-ATPase by phosphorylation catalyzed by Ca-dependent protein kinase [23]. In addition, $\mathrm{Ca}^{2+}$ is known to be involved in various aspects of $\mathrm{AC}$ functioning. Cytosolic $\mathrm{Ca}^{2+}$ forms a steep tip-directed gradient in pollen tubes required for regulating exocytosis during pollen tube growth and involves participation of $\mathrm{Ca}^{2+}$ in the modulating ROP1 GTPase activity [24]. As shown here, F-actin assembly and $\mathrm{Ca}^{2+}$ accumulation provide positive and negative feedback regulation of ROP1, respectively. In particular, the AF in pollen tubes occur in a polarized gradient overlapping with the tip-directed $\mathrm{Ca}^{2+}$ gradient [25], which can be explained via the $\mathrm{Ca}^{2+}$-dependence of actin organizing proteins which also control directional elongation in other cell types [26].

The results in this study showed that the membrane potential on pollen tube PM, cytosolic $\mathrm{pH}$ of pollen 
tubes, lateral membrane allocation of $\mathrm{PM} \mathrm{H}^{+}$-ATPase and organization of pollen tube $\mathrm{AC}$ are sensitive to hormonal treatments.

\subsection{Auxin IAA}

The important conclusion is that only in the case of auxin, all the observed hormone-induced responses of growing pollen tubes may be integrated into a common mechanism, in which $\mathrm{Ca}^{2+}$ ions can putatively serve as coordinative and integrating signal. IAA exerted monotonous alkalization of the cytoplasm of pollen tubes and the strongest effect on F-actin assembly, thereby suggesting the involvement of this hormone in the regulation of AF organization through corresponding modulation of the activity of $\mathrm{pH}$-sensitive actin binding proteins (ABPs). The auxin participation in the pollen tube polar growth was reported to be confirmed by PIN8 expression in the male gametophyte and its involvement in the regulation of intracellular auxin homeostasis [27]. Therefore, it can be concluded that auxin plays a key role in the maintenance of pollen tube polar growth that is in accordance with its similar behavior in other plant organs.

The directional transport of the auxin, central element of axis formation and patterning in plants, depends on gradients of auxin-efflux carriers that continuously cycle between PM and intracellular compartments. This cycling has been proposed to depend on $\mathrm{AF}$, while the organization of actin is under control of auxin [28]. Inhibition of auxin transport impaired the organization of actin in zygotes of the brown alga Fucus and inhibited signal-induced developmental polarity [29]. Auxin polar transport is essential for the development of zygote and embryo, and was correlated with $\mathrm{ABP} 1$ and $\mathrm{PM} \mathrm{H}^{+}$-ATPase activities [16]. Recently, it was found that the PM-located transmembrane kinase (TMK), receptor-like kinase (RLK), is capable of interacting with $\mathrm{ABP} 1$, thereby transducing auxin signal to activate PM-associated Rho of plants (ROPs). And as a result, these events lead to changes in the cytoskeleton and the shape of leaf cells in Arabidopsis [30]. Recent progress has been made towards the coordination of ROP signaling and trafficking of PIN transporters of auxin in both root and leaf cells [31]. To date, the data accumulated allow to settle the question whether auxin is a common polarizing signal acting through the conserved ROP GTPase to regulate cytoskeletal organization and vesicular trafficking [32].

\subsection{ABA}

To date, the available data indicate very important role of pollen $\mathrm{H}^{+}$-ATPase activity at the stage of pollen rehydration, when pollen grains take up water and have to adjust their turgor pressure to the water potential of the surrounding stigma surface [15]. The data in this study on the lateral membrane allocation of PM $\mathrm{H}^{+}$-ATPase accompanying pollen tube growth (Fig. 4) and ABA decline (Fig. 5) are in accordance with this conclusion as well. In the light of all these findings, it is suggested a participation of ABA in the maintenance of water status in pollen tubes. Interaction of IAA with $\mathrm{ABA}$ may be realized according to the hypothesis [33], suggesting a desiccation-associated ABA signaling transduction pathway, through which the LLP-Ropl gene is regulated during pollen dehydration in lily. LLP-ROP1 was shown to be localized in the cytoplasm along the pollen tube PM. In this case, in germinating pollen grains, ABA decreases, while ROP activity increases. Upon desiccation, the LLP-Rop1 gene is down-regulated and being a positive regulator of auxin [34] and negative regulator of ABA signal way [35]. Recently, Nibau et al. [36] reported that the Arabidopsis small GTPase AtRAC7/ROP9 (Arabidopsis RAC/ROP) functions as a modulator of both auxin and ABA signaling.

\subsection{Cytokinins}

The inhibitory effect of kinetin on pollen tube growth was related to degradation of F-actin along the 
length of the pollen tube. Apparently, both auxin and cytokinin play an important role in the regulation of the AC during pollen tube growth via their effects on actin polymerization. The hypothesis about the interaction of these hormones when applied to cytoskeleton has been formulated long ago [37]. At present, a lot of data in its favor were obtained. Ruzicka et al. [38] suggested that cytokinin affected auxin transport in the root meristem via the modification of PIN protein expression. According to $\mathrm{Li}$ et al. [39], auxin regulates spatial coordination of cell expansion in leaf interacting with $\mathrm{ABP} 1$ and activating Rho GTPases, while cytokinin inhibits ROP2 activity which regulates PIN1 distribution and suppresses morphogenesis in leaf. In this connection, the data of Bosch and Franklin-Tong [40] about the acidification of pollen tube cytoplasm, which accompanied mechanism of self-incompatibility, arouse interest. Wilkins et al. [41] showed that poppy pollen tubes undergoing a self-incompatible induction of programmed cell death exhibit a rapid acidification in the apical cytoplasm, together with an abrupt inhibition of growth, and argued that the increased acidity down-regulates actin depolymerizing factor (ADF) and thus prevents actin turnover, which is necessary for normal growth. Moreover, acidification of the cytoplasm plays a pivotal role in self-incompatibility-induced programmed cell death by creating optimal conditions for activation of the DEVDase/caspase-3-like activity.

\subsection{Gibberellins}

Although $\mathrm{GA}_{3}$ displayed the strongest stimulating action on petunia pollen tube growth, it, unlike IAA, practically had no any effect on F-actin organization as well as lateral membrane allocation of the pollen $\mathrm{PM} \mathrm{H}^{+}$-ATPase, and induced the increase in $\mathrm{pH}_{\mathrm{c}}$ only after 4 h-growth of pollen tubes. These observations did not allow us to make any certain conclusion on the mechanism of action of $\mathrm{GA}_{3}$. This opinion is consistent with the data earlier obtained by Singh et al.
[42] demonstrating only genetic evidence for $\mathrm{GA}_{3}$ promoting role in pollen tube growth. In this connection, the following explanation may be for these observations. IAA and gibberellins are known to be general growth factors involved in many plant developmental processes. A number of the observations suggest that there is crosstalk between the gibberellins and auxin. Willige et al. [43] showed that auxin transport is reduced in the inflorescences of Arabidopsis thaliana mutants deficient in biosynthesis of gibberellins. In particular, both the hormones were shown to play a major role in the onset of fruit development in Pyrus pyrifolia [44]. Here, authors designed the model for the hormone involvement in this process, where both positive and negative feedback loops are inherent in the signal transduction pathways of IAA and gibberellins. Moreover, it comprises cross-talks between them, in which IAA can promote the biosynthesis of gibberellins, but other growth regulators, such as $\mathrm{ABA}$, cytokinin and ethylene, can also play a role. The levels of pollen-derived gibberellins were closely related to enhanced pollen germination and increased pollen tube elongation. Applied gibberellins, and, by implication, elevated levels of endogenous gibberellins, are causally implicated in early growth of the fruitlet and fruit. Concentration of two growth-active gibberellins, $\mathrm{GA}_{3}$ and $\mathrm{GA}_{4}$, is positively correlated to pollen tube growth rate and final fruit size. It is hypothesized that a similar model for hormonal regulation of pollen tube growth may be valid in the case of petunia male gametophyte growth as well. The evidence in favor of this hypothesis, as follows from the results in the present work, is that endogenous concentrations of gibberellins increased in growing petunia pollen tubes [10], while exogenous gibberellins showed the strongest stimulating effect on their germination and growth.

\section{Conclusions}

The findings of the present work allow us to 
conclude that the main, if not key, target of exogenous plant hormones action is represented by pollen PM $\mathrm{H}^{+}$-ATPase, which plays a crucial role in hormone-induced pollen tube germination and growth as well as the related processes based on the activation of ion and water transport across the PM. The results obtained provide evidence that the hormonal stimulation of the activity of this enzyme, putatively mediated by $\mathrm{Ca}^{2+}$ ions appears to be closely associated with ion transport through pollen $\mathrm{PM}$ and the hormone-induced reorganization of the AC. All these data, taken together, suggest that the effects in question may underlie the hormonal signaling in growing pollen tubes.

\section{Acknowledgments}

This work was supported by grant from the Russian Foundation for Basic Research (RFBR No. 10-04-00356 and 13-04-00592).

\section{References}

[1] Feijo, J. A., Malho, R., and Obermeyer, G. 1995. "Ion Dynamics and Its Possible Role during in Vitro Pollen Germination and Tube Growth.” Protoplasma 187 (1): 155-67.

[2] Feijo, J. A., Sainhas, J., Hackett, G. R., Kunkel, J. G., and Hepler, P. K. 1999. "Growing Pollen Tubes Possess a Constitutive Alkaline Band in the Clear Zone and a Growth-Dependent Acidic Tip.” J. Cell Biology 144: 483-96.

[3] Vidali, L., McKenna, S. T., and Hepler, P. K. 2001. "Actin Polymerization Is Essential for Pollen Tube Growth." Mol. Biol. Cell 12 (8): 2534-45.

[4] Holdaway-Clarke, T. L., and Hepler, P. K. 2003. "Control of Pollen Tube Growth: Role of Ion Gradients and Fluxes." New Phytol. 159 (3): 539-63.

[5] Cheung, A. Y., Duan, Q. H., Costa, S. S., De Graaf, B. H., Di Stilio, V. S., Feijo, J., and Wu, H. M. 2008. "The Dynamic Pollen Tube Cytoskeleton: Live Cell Studies Using Actin-Binding and Microtubule-Binding Reporter Proteins." Mol. Plant 1 (4): 686-702.

[6] Fu, Y. 2010. "The Actin Cytoskeleton and Signaling Network during Pollen Tube Tip Growth.” J. Integr. Plant Biology 52 (2): 131-7.

[7] Lang, V., Pertl-Obermeyer, H., Safiarian, M. J., and Obermeyer, G. 2014. "Pump up the Volume: A Central Role for the Plasma Membrane $\mathrm{H}(+)$ Pump in Pollen
Germination and Tube Growth." Protoplasma 251 (3): 477-88.

[8] Hepler, P. K. 2016. "The Cytoskeleton and Its Regulation by Calcium and Protons." Plant Physiol. 170 (1): 3-22.

[9] Kovaleva, L., and Zakharova, E. 2003. "Hormonal Status of the Pollen-Pistil System at the Progamic Phase of Fertilization after Compatible and Incompatible Pollination in Petunia hybrida L.." Sex. Plant Reprod. 16 (4): 191-6.

[10] Kovaleva, L. V., Zakharova, E. V., Minkina, Y., Timofeeva, G. V., and Andreev, I. M. 2005. "Germination and in Vitro Growth of Petunia Male Gametophyte Are Affected by Exogenous Hormones and Involve the Changes in the Endogenous Hormone Level." Russian J. Plant Physiol. 52 (4): 521-6.

[11] Andreev, I. M., Timofeeva, G. V., Minkina, Y. V., and Kovaleva, L. V. 2007. "Effects of Exogenous Phytohormones on Intracellular $\mathrm{pH}$ of Petunia hybrida Pollen Grains.” Russian J. Plant Physiol. 54 (5): 626-32.

[12] Kovaleva, L. V., Zakharova, E. V., Minkina, Y. V., and Voronkov, A. S. 2009. "Effects of Flavonols and Phytohormones on Germination and Growth of Petunia Male Gametophyte." Allelopathy J. 23 (1): 51-62.

[13] Voronkov, A. S., Andreev, I. M., Timofeeva, G. V., and Kovaleva, L. V. 2010. "Stimulation of Electrogenic Activity of $\mathrm{PM} \mathrm{H}^{+}$-ATPase in Petunia Germinating Male Gametophyte by Exogenous Auxin: Mediator Role of Calcium and Reactive Oxygen Species." Russian J. Plant Physiol. 57: 401-7.

[14] Kovaleva, L. V., Voronkov, A. S., and Zakharova, E. V. 2015. "Role of Auxin and Cytokinin in the Regulation of the Actin Cytoskeleton in the in Vitro Germinating Male Gametophyte of Petunia." Russian J. Plant Physiol. 62 (2): 179-86.

[15] Pertl, H., Pockl, M., Blaschke, C., and Obermeyer, G. 2010. "Osmoregulation in Lilium Pollen Grains Occurs via Modulation of the Plasma Membrane $\mathrm{H}^{+}$-ATPase Activity by 14-3-3 Proteins." Plant Physiol. 154 (4): 1921-8.

[16] Chen, D., Ren, Y., Deng, Y., and Zhao, J. 2010. “Auxin Polar Transport Is Essential for the Development of Zygote and Embryo in Nicotiana tabacum L. and Correlated with ABP1 and PM H $\mathrm{H}^{+}$-ATPase Activities." $J$. Exp. Bot. 61 (6): 1853-67.

[17] Wang, L., Liu, Y. M., and Li, Y. 2005. "Comparison of F-Actin Fluorescent Labeling Method in Pollen Tubes of Lilium davidii." Plant Cell Rep. 24 (5): 266-70.

[18] Fricker, M. D., White, N. S., and Obermeyer, G. 1997. "pH Gradients Are Not Associated with Tip Growth in Pollen Tubes of Lilium longiflorum." J. Cell Sci. 110: 1729-40.

[19] Skorobogatova, I. V., Zakharova, E. V., Karsunkina, N. 

Identification of Their Potential Targets

P., Kurapov, P. B., Sorkina, G. I. L., and Kislin, E. N. 1999. "Changes in the Content of Phytohormones in Barley Seedlings during Ontogenesis and in the Presence of Growth-Stimulated Regulators." Agrokhimiya 8: 49-53.

[20] Brault, M., Amiar, Z., Pennarun, A. M., Monestiez, M., Zhang, Z., Cornel, D., Dellis, O., Knight, H., Bouteau, F., and Rona, J. P. 2004. "Plasma Membrane Depolarization by Abscisic Acid in Arabidopsis Suspension Cells Involves Reduction of Proton Pumping in Addition to Anion Channel Activation, Which Are Both $\mathrm{Ca}^{2+}$ Dependent." Plant Physiol. 135 (1): 231-43.

[21] Certal, A. C., Almeida, R. B., Carvalho, L. M., Wong, E., Moreno, N., Michard, E., Carmeiro, J., Rodriguezleon, J., Wu, H. M., Cheung, A. Y., and Feijo, J. A. 2008. "Exclusion of a Proton ATPase from the Apical Membrane Is Associated with Cell Polarity and Tip Growth in Nicotiana tabacum Pollen Tubes." Plant Cell 20 (3): 614-34.

[22] Himschoot, E., Beeckman, T., Friml, J., and Vanneste, S. 2015. "Calcium Is an Organizer of Cell Polarity in Plants." Biochemica et Biophysica Acta 1853 (9): 2168-72.

[23] Yu, X. C., Li, M. J., Gao, G. F., Feng, H. Z., Geng, X. Q., Peng, C. C., Zhu, S. Y., Wang, X. J., Shen, Y. Y., and Zhang, D. P. 2006. "Abscisic Acid Stimulates a Calcium-Dependent Protein Kinase in Grape Berry." Plant Physiol. 140 (2): 558-79.

[24] Yan, A., Xu, G., and Yang, Z. B. 2009. "Calcium Participates in Feedback Regulation of the Oscillating ROP1 Rho GTPase in Pollen Tubes." Proc. Natl. Acad Sci. USA 106 (51): 22002-7.

[25] Fan, X., Hou, J., Chen, X., Chaudhry, F., Staiger, C. J., and Ren, H. 2004. "Identification and Characterization of a $\mathrm{Ca}^{2+}$-Dependent Actin Filament-Severing Protein from Lily Pollen." Plant Physiol. 136 (4): 3979-89.

[26] Huang, Y. W., Chang, S. J., I-Chen Harn, H., Huang, H. T., Lin, H. H., Shen, M. R., Tang, M. J., and Chiu, W. T. 2015. "Mechanosensitive Store-Operated Calcium Entry Regulates the Formation of Cell Polarity." J. Cell Physiol. 230 (9): 2086-97.

[27] Dal Bosco, C., Dovzhenko, A., and Palme, K. 2012. "Intracellular Auxin Transport in Pollen: PIN8, PIN5 and PILS5." Plant Signal. Behav. 7 (11): 1504-5.

[28] Nick, P., Han, M. J., and An, G. 2009. “Auxin Stimulates Its Own Transport by Shaping Actin Filaments." Plant Physiol. 151 (1): 155-67.

[29] Sun, H. G., Basu, S., Brady, S. R., Luciano, R. L., and Muday, G. K. 2004. "Interactions between Auxin Transport and Actin Cytoskeleton in Developmental Polarity of Fucus distichus Embryos in Response to Light and Gravity." Plant Physiol. 135 (1): 266-78.

[30] Xu, T., Dai, N., Chen, J., Nagawa, S., Cao, M., Li, H.,
Zhou, Z., Chen, X., De Rycke, R., Rakusová, H., Wang, W., Jones, A. M., Friml, J., Patterson, S. E., Bleecker, A. B., and Yang, Z. 2014. "Cell Surface ABP1-TMK Auxin-Sensing Complex Activates ROP GTPase Signaling." Science 343 (6174): 1025-8.

[31] Chen, X., and Friml, J. 2014. "Rho-GTPase-Regulated Vesicle Trafficking in Plant Cell Polarity." Biochem. Soc. Trans. 42 (1): 212-8.

[32] Pan, X., Chen, J., and Yang, Z. 2015. “Auxin Regulation of Cell Polarity in Plants." Current Opinion in Plant Biology 28: 144-53.

[33] Hsu, S. W., Cheng, C. L., Jason, T. C., and Wang, C. S. 2010. "Rop GTPase and Its Target Cdc42/Rac-Interactive-Binding Motif-Containing Protein Genes Respond to Desiccation during Pollen Maturation." Plant Cell Physiol. 51 (7): 1197-209.

[34] Tao, L. Z., Cheung, A. Y., Nibau, C., and Wu, H. M. 2005. "RAC GTPases in Tobacco and Arabidopsis Mediate Auxin-Induced Formation of Proteolytically Active Nuclear Protein Bodies that Contain AUX/IAA Proteins." Plant Cell 17 (8): 2369-83.

[35] Xin, Z. Y., Zhao, Y. H., and Zheng, Z. L. 2005. "Transcriptome Analysis Reveals Specific Modulation of Abscisic Acid Signaling by ROP10 Small GTPase in Arabidopsis." Plant Physiol. 139 (3): 1350-65.

[36] Nibau, C., Tao, L., Levasseur, K., Wu, H. M., and Cheung, A. Y. 2013. "The Arabidopsis Small GTPase AtRAC7/ROP9 Is a Modulator of Auxin and Abscisic Acid Signaling." J. Exp. Bot. 64 (11): 3425-37.

[37] Grabski, S., and Schindler, M. 1996. "Auxins and Cytokinins as Antipodal Modulators of Elasticity within the Actin Network of Plant Cells." Plant Physiol. 110 (3): 965-70.

[38] Ruzicka, K., Simaskova, M., Duclercq, J., Petrasek, J., Zazimalova, E., Simon, S., Friml, J., Van Montagu, M. C., and Benkova, E. 2009. "Cytokinin Regulates Root Meristem Activity via Modulation of the Polar Auxin Transport." Proc. Natl. Acad. Sci. USA 106 (11): 4284-9.

[39] Li, H., Xu, N., Lin, D., Wen, M., Xie, M., Duclercq, J., Bielach, A., Kim, J., Reddy, G. V., Zuo, J., Benkova, E., Friml, J., Guo, H., and Yang, Z. 2013. "Cytokinin Signaling Regulates Pavement Cell Morphogenesis in Arabidopsis." Cell Res. 23 (2): 290-9.

[40] Bosch, M., and Franklin-Tong, V. E. 2007. "Temporal and Spatial Activation of Caspase-Like Enzymes Induced by Self-incompatibility in Papaver Pollen." Proc. Natl. Acad. Sci. USA 104 (46): 18327-32.

[41] Wilkins, K. A., Bosch, M., Haque, T., Teng, N., Poulter, N. S., and Franklin-Tong, V. E. 2015. "Self-incompatibility Induced Programmed Cell Death in Field Poppy Pollen Involves Dramatic Acidification of the Incompatible Pollen Tube Cytosol." Plant Physiol. 
167 (3): 766-79.

[42] Singh, D. P., Jermakow, A. M., and Swain, S. M. 2002. "Gibberellins Are Required for Seed Development and Pollen Tube Growth in Arabidopsis." Plant Cell 14 (12): 3133-47.

[43] Willige, B. C., Isono, E., Richter, R., Zourelidou, M., and Schwechheimer, C. 2011. "Gibberellin Regulates
PIN-Formed Abundance and Is Required for Auxin Transport-Dependent Growth and Development in Arabidopsis thaliana." Plant Cell 23 (6): 2184-95.

[44] Zhang, C., Tateishi, N., and Tanabe, K. 2010. "Pollen Density on the Stigma Affects Endogenous Gibberellin Metabolism, Seed and Fruit Set, and Fruit Quality in Pyrus pyrifolia.” J. Exp. Bot. 61 (15): 4291-302. 